\title{
A review of the occurrence and clinical consequences of protozoan infections in carnivorous fur farm animals
}

\author{
Maciej Klockiewicz ${ }^{1, A-B, D, F} \oplus$, Ewa Długosz ${ }^{1, D-F} \oplus$, Tadeusz Jakubowski ${ }^{1, B-C, E} \oplus$ \\ ${ }^{1}$ Warsaw University of Life Sciences-SGGW, Poland \\ A - Research concept and design, B - Collection and/or assembly of data, C - Data analysis and interpretation, \\ $D$ - Writing the article, E - Critical revision of the article, F- Final approval of article
}

Klockiewicz M, Długosz E, Jakubowski T. A review of the occurrence and clinical consequences of protozoan infections in carnivorous fur farm animals. Ann Agric Environ Med. 2021; 28(2): 199-207. doi: 10.26444/aaem/120974

\begin{abstract}
Introduction and Objective. The aim was to review available data concerning the occurrence of protozoan parasites affecting carnivorous fur farm animals, such as: American mink, blue and silver foxes, and raccoon dogs. Although, many protozoan pathogens have been isolated in wild fur animals, some are still not recognised as relevant to particular fur farm animal species. Protozoans that have been isolated as causative agents of clinical cases and reported in these animals are: Cryptosporidium spp., Eimeria spp., Isospora spp., Leishmania infantum, Neospora caninum, Sarcocystis spp., and Toxoplasma gondii. Unfortunately, in most reports, neither clinical symptoms nor detailed pathogenicity and clinical pathology are satisfactory discriminated. This data is essential for preparing treatment and preventive measure protocols. Additionally, attempts to better understand the infections might be useful in the case of outbreaks.

Results. The results of the literature research revealed that some detected infections may have zoonotic potential, and are quite likely to be transmitted in both directions. The role of vectors, e.g. small rodents, birds, insects (sand-flies), or pets (cats and dogs), which might be involved in the transmission of various parasitic infections, is also discussed. The summarized list of protozoans involved can be used for further studies on the health and welfare aspects of fur farm animal breeding and public health issues.
\end{abstract}

\section{Key words}

epidemiology, clinical symptoms, farm carnivorous fur animals, protozoan infection

\section{INTRODUCTION}

Parasitic infections are common in naturally living carnivorous fur animals. It is generally assumed that parasite infections may have some impact on the development and productivity of fur animals reared on farms. Although farm animals should be protected from natural resources of infections, in some circumstances they might be exposed to invasive forms of parasite. It is therefore very important to recognize possible source(s) of infections in order to limit their impact on health status and welfare in farm fur animals. Hence, the aim of this review is to indicate the protozoan parasites that have been found to affectthese animals.

Farmed blue (arctic) foxes (Alopex logopus), silver foxes (Vulpes vulpes), mink (American mink - Neovison vison), raccoon dogs (Nyctereutes procyonoides), sable (Martes zibellina), etc., might eventually be involved in the life cycles of different ecto- and endo-parasites. Closely related species - fur animals living in nature - usually play the role of definitive hosts (as predators), but their prey serves as intermediate or paratenic hosts. Farm conditions generally limit the contribution risk of parasitic infections, but it seems that some parasites remain a real threat to these animals. Unfortunately, among the infections there are some which are considered potentially zoonotic, which means that they

Address for correspondence: Maciej Klockiewicz, Institute of Veterinary Medicine, Warsaw University of Life Sciences-SGGW Poland

E-mail: maciej_klockiewicz@sggw.edu.pl

Received: 09.01.2020; accepted: 23.04.2020; first published: 01.06.2020 could subsequently also be a direct health and/or risk to life for humans.

Overview of infections. There are several species of protozoans recognised as pathogenic in fur farm animals. Their importance has increased and become more intensely studied at present.

The infections caused by Cryptosporidium spp. are quite frequently found in humans, pets and farm animals. Moreover, several species/genotypes of these protozoans found in animals are considered as zoonotic. Similar to other hosts, cryptosporidia affecting farm foxes, mink and raccoon dogs, are involved in diarrheal episodes, but these have also been isolated from asymptomatic carriers. Generally, descriptions of outbreaks and the clinical course of cryptosporidiosis in fur animals is rather scarce.

The prevalence and species composition involved in reported Cryptosporidium spp. infections are also distinct, for example, C. canis has been detected in $1.6 \%$ of silver foxes, $10.5 \%$ raccoon dogs and $29.6 \%$ in mink [1]. Although these protozoans occurred exclusively in silver foxes and raccoon dogs, two more parasite species were found in mink: C. meleagridis and Cryptosporidium - mink genotype. Interestingly, the prevalence was equal in both, 5-6-monthold whelps and adults silver foxes, but in mink they were detected only in 5-6-month-old animals.

C. canis infection has also been reported in blue foxes [2], 48 isolates of C. canis were detected, with an overall prevalence of $15.9 \%$. Among farms, prevalence varied from $0-31.4 \%$. Comparison of age groups showed a slightly 
increasing prevalence from $14.1 \%$ in pre-weaned puppies, $15.6 \%$ in whelps and $19 \%$ in adults, respectively. Results of another study showed that the percentage of cryptosporidia parasites found in foxes was $5.6 \%$ and $7.0 \%$ in mink [3]. On the contrary, infection was not detected in raccoon dogs. Most often, C. canis was demonstrated both in foxes and mink, but C. meleagridis and Cryptosporidium-mink type alone in foxes and mink, respectively. Earlier, one additional isolate of C. ubiquitum (XIIa subtype family) was identified in a single farm mink [4].

Other isolates have also been found living in wild fur animals; for example, C. canis and C. macropodum-like were isolated from foxes (prevalence $-10.5 \%$ ), C. canis and C. hominis-like in dingoes (prevalence 22.7\%) [5]. C. andersoni was detected in 5\% of wild American mink (Mustela vison) [6]. C. canis was also isolated in mongoose and red foxes; C. felis in a red fox; C. hominis in a badger, C. parvum and C. ubiquitum again in single red foxes, respectively [7]. Until now, raccoon dogs were found infected only with C. parvum [8] or C. canis [9]. Numerous Cryptosporidium spp. oocysts were detected in $17.6 \%$ of wild raccoon dog faecal samples in south-west Poland. The same host was found to be infected with Entamoeba spp., as a number of cysts were detected by direct faecal smear [10]. These parasites are also considered to be zoonotic, but the pathogenicity in fur animals remains to be explained.

As a consequence, the question arises whether the detection of particular cryptosporidia oocysts (C. hominis, C. parvum, C. ubiquitum) in wild carnivores took place as a result of contribution and natural infection, and/or it was possibly an artefact due to previous contact with human origin biological material. As shown above, reared fur animals could be exposed to cryptosporidiosis and/or they might be involved in the transmission of that infection to humans.

Intestinal coccidiosis in foxes and mink - Isosporosis. A case of severe intestinal isosporosis in farm silver foxes was reported in Finland [11], in which two subsequent courses of the infection took place on the same farms. The outbreaks resulted in clinically expressed enteritis in whelps of both blue as well as silver foxes. Two Isospora species were identified as the causative agents of the outbreaks. Morphological examination revealed I. canivelocis and slightly smaller ones that certainly resembling I. ohioensis. It was pointed out that the former might have been identical with other species, including I. canis.

The reported infection took place in puppies of silver foxes. The symptoms were noticed in all animals, but the disease seriously affected half of them (morbidity of 50\%), but no increase in mortality was observed. Clinically, three weeks old pups showed watery faeces, dehydration, and moist, ruffled coat. Although still being nursed, the affected whelps were markedly smaller in terms of body size and poorer growth. The second infection occurred in blue fox whelps, but the clinical symptoms appeared earlier and resulted in lower body weight gain. Interestingly, the course of infection was more severe and morbidity higher in blue than silver foxes, respectively. A similar picture of intestinal Isospora spp. infection is usually observed in the puppies of dogs [12].

The main aspect of treatment of intestinal coccidiosis must be based on the usage of medicines recommended for carnivorous domestic pets (cats and dogs). Therefore, whelps were saturated with potentiated sulfonamides (sulphadiatizine-trimethoprim /ratio 5:1/ - dosage 120 ppm in semi-moist feed for five days), or a combination of toltrazuril per os at $10 \mathrm{mg} / \mathrm{kg}$ bw, followed by sulfonamides, as above. The therapy in blue foxes was found to be more effective than in silver foxes [11].

Intestinal coccidiosis of mink. The infection may result in increased mortality mainly in kits, and occurs more often in old-fashioned facilities where the animals are kept on the ground or in pens with board flooring. The introduction of wire bottom boxes considerably limited the number of outbreaks in mink [13]. In another case, increased oocyst shedding was observed in the faeces of adult female mink, from parturition to weaning of the kits [14].

Researchers summarizing data concerning coccidian parasites found in carnivores, published a list of four Eimeria species in mink: E. furonis, E. hiepei, E. mustelae, and E. vison [15]. Later, in the USA, E. mustelae, E. vison, Isospora bigemina and I. laidlawi were noted as coccidian parasites responsible for the disease in mink [13]. In south-west Poland, oocysts of the genus Cystoisopora (probably C. canis) were also discovered in $1 / 3$ of faecal samples obtained from wild raccoon dogs [10]. Another study on Polish fur animals farms revealed the presence of Isospora sp. oocysts in foxes, mink and raccoon dogs manure [16]. The prevalence of coccidiosis in mink during the seasons varied from $10 \%-56 \%$, but it was rather non-essential in two other host-species. Coccidia oocysts were detected in faecal samples of all surveyed mink farms (located mainly in western Poland), but the intensity of oocyst excretion was estimated at a low level [17]. Isospora $s p$. oocysts were noted only in two out of nine investigated mink farms in eastern Poland [18]; however, three coccidia species, Isospora laidlawi, Eimeria mustelae and E. vison, were identified in coprological analysis in a farm located in southern Poland [19]. The intensity was estimated as quite low (70-730 oocysts per $1 \mathrm{~g}$ of faeces) and recognised as clinically irrelevant because the mink stayed healthy until the end of the rearing period.

During recently performed studies in Denmark, a new parasite named Eimeria vison-like, because it mostly resembled E. vison, was found and characterized using morphological and molecular analysis [20]. It was concluded that the occurrence of coccidians, in particular on mink farms, may vary considerably, depending on the locality.

Apart from the biological aspects, it may be assumed that infection preferably affects kits and young mink, and usually begins with mucus-coated faeces, lethargy, followed by more pronounced enteritis. The symptoms might not always be clear-cut and specific. Affected individuals usually present a rough and dull coat. Symptoms are observed for one to two months, and may continue as a chronic infection, causing mink become carriers [13]. The severity of the disease depends on the immune status of the affected mink, and can also be significantly influenced by Aleutian and distemper infections.

Contrary to the therapy for foxes, the use of sulfonamides is not recommended to treat coccidiosis in mink because, e.g. sulfaquinoxaline is considered as very toxic to these animals [13]. However, another group used two anticoccidials: lasalocid and an antibiotic-sulfonamide preparation to determine the impact on coccidia infection in growing mink [14]. This resulted in reduced mortality, but non-significant for weight gains. Russian researchers tested a treatment 
method based on toltrazuril given with feed at a dose of $30 \mathrm{mg} / \mathrm{kg}$ bw for two consecutive days, which was found to be the most appropriate for adult mink, and patented (RussianPatents.com /patent/242/2425678.html).

Toxoplasma gondii - a zoonotic infection in fur animals. Among many protozoans affecting fur animals, T. gondii remains the main issue as commonly occurring worldwide. Although its only definitive host are the felids, the parasite is being widely-spread and all fur farmed animals are at risk of infection. These serve only as an intermediate hosts, due to which the animals affected by $T$. gondii during the course of infection might develop clinical symptoms, such as abortion and other general health disorders.

Carnivorous fur animals contract toxoplasmosis by the ingestion of sporulated oocyst, or the tissue cysts of any host by-products of slaughtered animals which are contained in feed, and/or accidentally via consumed small rodents. Definitively, infection is related to the type of diet fed to the animals. It was concluded that the use of raw, nonfrozen slaughter offal and carcasses may result in loses due to T. gondii infections [21].

The total prevalence of anti-T. gondii antibodies in fox sera during the surveyed study on toxoplasmosis in farmed foxes in Poland, was determined at 33.6\% [22]. This was confirmed in most of the selected farms (11 out of 14). It has to be pointed that farms found to be negative presented higher standards of hygiene. The serological data was subsequently confirmed by immunofluorescence examinations of impression slides of the parenchymal tissues of brain, liver, lungs and spleen. Moreover, the highest detected titers were noted in females which lost their puppies due to abortion, or a few days after delivery.

Clinical toxoplasmosis was diagnosed in three fourmonth-old farm polar (blue) fox-pups in Poland [23]. Those affected manifested a set of general symptoms: normal or slightly increased body temperature $\left(39-40^{\circ} \mathrm{C}\right.$ vs. $41^{\circ} \mathrm{C}$, respectively), tachypnoea, and some were diarrhoeic. More specific neurological signs followed: photophobia, lacrimation, single bad cough, ataxia and paraplegia. Despite treatment, the affected foxes died within three-five days. Histopathological examination revealed T. gondii cysts in the parenchyma of brain and kidneys. The diagnosis was in accordance with previous records of reproduction failures noted on the same farm.

An outbreak of toxoplasmosis in silver foxes was determined as a septicaemic disease [24]. It was found to be associated with the prophylactic vaccination programme carried out on the farm. Animals presented severe clinical symptoms of toxoplasmosis due to two subsequent immunisations, followed by transient and significant immunosuppression. The infection was characterised as a fulminating, septicaemic disease with high morbidity. Histopathology revealed that Toxoplasma parasites mostly affected brain and spleen, but they were also noted in all parenchymal organs. It was concluded that the infection should be considered in differential diagnosis in any case of sudden deaths, or neurological symptoms found in farmed foxes.

The occurrence of toxoplasmosis was investigated in a farm located in the Wielkopolska Region of Poland [25]. The PCR detected T. gondii infection in muscle samples in five out of ten red fox whelps. The result of an anal swab test was positive for T. gondii in adult and pups of red foxes (4/24 and 1/10 respectively), and in raccoon dogs (3/3 of adults and $3 / 7$ of juveniles), but this was contentious as all the tested species are known to be intermediate but not final hosts. Such a result could be explained by the fact that the animals were fed raw carcass meat obtained from an abattoir where the animals were possibly infected with $T$. gondii. The hygiene standards and biosecurity at the location were noted as 'not that high', and cats and small rodents had access to the farm.

Clinical toxoplasmosis was diagnosed in both red and arctic wild fox species. T. gondii was found as a causative agent of three dead arctic foxes in Norway [26]. Post-mortem examinations revealed advanced jaundice in an adult and multi-focal, acute, necrotizing hepatitis, acute interstitial pneumonia, scattered foci of brain gliosis, usually associated with Toxoplasma tachyzoites. Toxoplasma-associated meningitis in one pup was also noted. The infection was determined by immunohistochemistry and anti-T. gondii antibodies in sera detected in all affected animals.

In the same region, it was found that the prevalence of T. gondii in wild arctic foxes reached $43 \%$, as measured by direct agglutination test [27]. As there was no cats or wild felids, the authors suggested the involvement of migratory birds (barnacle goose), and vertical transmission (particularly enhancing factor) in the epidemiology of toxoplasmosis in that region. The parasite was isolated and genetically characterised to discover the potential source of toxoplasmosis in artic foxes in that area [28]. It was proved that the infectivity of isolates was via the mice model by oral challenge, with brain and/or heart Toxoplasma cysts. Cats infected per os with mice tissues excreted T. gondii oocysts in their faeces. PCR-RFLP genetic analysis with ten markers followed by DNA sequencing revealed that it was the Type II strain, which is the predominant T. gondii lineage worldwide (e.g. North America and Europe). Further studies confirmed the predomination of that archetype and highlighted the significance of possible long-distance birdsmediated transmission of T. gondii infection in arctic foxes [29]. Such a way of transmission would have occurred via birds living nearby fur animal farms.

Using a commercial ELISA test, several seropositive animals (13\%) among wild Far Eastern forest cats and American mink examined in Primorsky Krai in the Russian Far East were identified. Only one out of 34 cats and nine out of 21 dogs among stray and/or feral animals examined in that region were seropositive [30].

Contrary to foxes, there are single reports on farm mink toxoplasmosis. One of the earliest clinical records of farm mink toxoplasmosis was published in 1958, which was a detailed description of several outbreaks observed in Canada [31]. Mink demonstrated numerous neurological symptoms, such as: unusual rushing in and out of the nest box, an extreme shyness (hiding as much as possible), exophthalmia, urinating and defecating randomly all over the box. The affected mink had anorexia, limited drinking water which resulted in gradual loss of condition, and death due to dehydration. The mink had problems with mobility and balance, showed reluctance to raise their heads, stood with their feed spread wide apart, and kept their tails in a squirrellike manner; tails and feet were frozen and necrotic.

Toxoplasmosis also resulted in abnormalities of reproduction, e.g. copulation - males fully extended the penis before mating, but finally were unable to complete the coitus act. Infected females killed their kits about a month 
after delivery, others did not nurse their deformed kits and left them to die outside the nest. None of surviving weaned kits developed the disease, even though many of their mothers died. Morbidity was as high as $90-100 \%$, and all animals that expressed signs of infection subsequently died (mortality on some farms was $100 \%)$.

T. gondii infection was also diagnosed in Danish farm mink [32]. There were high titers (1:64) noted in a single mink; estimated prevalence $-3 \%$. Based on that, the authors predicted that the real number of infected (seropositive) animals to be about 300,000 (vs. 1 million reared on 17 surveyed farms). The numbers at that time showed the scale of problem - many farm mink were at risk of contributing and developing clinical toxoplasmosis.

Probably one of the most severe outbreaks caused by T. gondii in farm mink was reported from Wisconsin, USA [33]. The disease affected almost $2 \%$ of 7,800 females, which had aborted or neonatal mortality. The clinical signs attributed to the toxoplasmosis had occurred in 10,408 kits and about $1 / 3$ of the kits died at one to three weeks of age. Prior to delivery, pregnant mink showed a decreased appetite, and in the affected offspring, mainly ataxia and weakness followed by death were observed. Post-mortem examination of the kits revealed empty stomachs, pale livers, and distended urinary bladders. Detailed description of HE (Haematoxylin Eosin staining) slides of parenchymal organs revealed advanced interstitial pneumonia, severe encephalomalacia and myocarditis. The presence of T. gondii tachyzoites was visualised by immunochemistry in tissues of the organs.

Toxoplasmosis was also confirmed in Polish farm mink [34]. The infection was diagnosed serologically by latex agglutination test in $13.8 \%$ of examined individuals, and the prevalence was significantly higher in smaller (26.3\%) than in large farms (2.9\%). The occurrence of infection was distinctly related to the feed resources as it was mostly found in mink fed on by-products of non-frozen slaughtered animal origin $(43.4 \%)$ rather than fish $(2.2 \%)$. The pathogenicity of the infection was also confirmed by the immunofluorescence method of impression smears of the parenchymal organs - liver and brain of single neonatal kits. It was observed that reproduction parameters seemed to be affected by the infection. However, this could be explained by co-infection with Aleutian disease (ADV). The authors repeated the opinion that other viral infections might be involved in the co-pathogenesis of parasitic diseases in farm mink, e.g. distemper and ADV.

Other researchers estimated the seroprevalence of T. gondii infection in farm mink in north-east China [35]. The infection was detected by different tests: MAT (Modified Agglutination Test), ELISA (with three different antigens GRA1, GRA7 and TSA) and Western blotting. Comparison of results indicated that GRA7-ELISA was found to be the most accurate to investigate T. gondii infection in farm mink, and recommended caution while using MAT. Despite the test used, it was concluded that prevention and control of toxoplasmosis had to be improved.

Neospora caninum infection is an another protozoan-born disease identified in farm foxes. However, the prevalence of infection in farmed foxes in Poland was found to be rather low (1.7\%), but the same range-level was found in wild red foxes (4.4\%) [21]. However, the authors noted that individuals positive for N. caninum were negative to T. gondii and suggested that foxes play a rather minor role in the epidemiology of canine neosporosis.

A higher prevalence of $N$. caninum was identified in Great Britain [36]. The infection was diagnosed by specific ITS1 nested PCR in $18.6 \%$ of polecats, $10.9 \%$ of badgers, $10.1 \%$ of ferrets, $4.8 \%$ of red foxes and $4.6 \%$ of American mink. It could be assumed that both wild red foxes and mink are negligible in the transmission of this disease.

In contrast, infections caused by Sarcocystis spp. in farm mink have been observed in the USA with signs of progressive neurological and/or skeletal disease. The first published report presented a case of meningoencephalitis in one-month-old kits originating from a small size farm (15,500 mink). They were weak, ataxic, dysphagic, and finally comatose prior to dissection. Fifty more dead kits were found within two weeks on the same farm. Moreover, abortions were recorded as well as foetal loss during the kindling season. Microscopic analysis of $\mathrm{HE}$ slides revealed extensive necrotic foci of the cerebral cortex, and inflammatory infiltrate (mainly of neutrophils, some macrophages and lymphocytes) involving the entire gyrus. Multifocal abscessation, angiocentric accumulations of leucocytes, vasculitis, meningitis and gliosis were noted in the surrounding parenchyma brain areas. Protozoans were described by Transmission Electron Microscopy (TEM) as remaining parasites of the genus Sarcocystis. Differential immunohistochemical test excluded T. gondii and N. caninum infections, but confirmed involvement of Sarcocystis sp. HE slides additionally revealed histiocytic-lymphocytic interstitial pneumonitis and mild histiocytic-lymphocytic myocardidtis, respectively, which explained the very poor condition of the kits. Considering these findings, the parasite was described as being more similar to Sarcocystis neurona (causative agent of horse myeloencephalitis - EPM) than to $S$. canis. In conclusion, the very young age of the affected mink and acute course of the infection were underlined [37].

Sarcocystis infection was also diagnosed in single two to three-month-old farm mink kits [38]. Muscle tissue examination revealed numerous sarcocysts containing both metrocytes and bradyzoites in striated muscles. The lesions were associated with non-suppurative meningoencephalitis and meningomyelitis. There were two more deaths among mink at the same farm, but lesions of skeletal muscles were no longer noted.

It is worth noting that fur carnivorans living in the wild are quite likely to contribute to Sarcocystis spp. infections. Their oocysts/sporocysts were detected directly in $17.4 \%$ faecal samples and $20 \%$ of mucosal scrapings of red foxes, and $53.8 \%$ of mucosal scrapings of raccoon dogs in Lithuania. Those protozoans were discriminated by PCR as $S$. rileyi - a new parasite in Europe with ducks as an intermediate host, and red foxes and raccoon dogs serving as the definitive host [39].

Sarcocystosis was found in examined wild red foxes and raccoon dogs of the Brandenburg region in Germany [40]. The authors performed flotation with mucosal scrapings to isolate oocysts/sporocysts of the intestines. Using molecular analysis, it was found that some individuals of both hostspecies were infected with Sarcocystis spp. The following species were found in red foxes: S. tenella (or S. capracanis) (10\%), S. miescheriana (8\%), S. gracilis (8\%), Sarcocystis spp. infecting birds as intermediate hosts (6\%), and S. capreolicanis (4\%). In raccoon dogs, S. miescheriana (18.4\%), S. gracilis (13.1\%), Sarcocystis spp. using birds as intermediate hosts $(10.5 \%)$, S. tenella (or S. capracanis) and S. capreolicanis $(2.6 \%)$ 
were noted. It was concluded that the method applied in the study gave a higher prevalence ratio of positive results than standard coprology. It also helped to obtain more information on potential definitive hosts of these protozoans.

Giardia duodenalis infections. It is worth noting that - to the best of the authors' knowledge - despite the laboratory services offered, to-date, no veterinary/scientific reports have been published on the clinical aspects of giardiosis in fur farm animals.

Giardiasis was reported in selected fur pet species in which isolated G. duodenalis sequences were found to be identical to sub-assemblages AI or BIV from ferrets - fur carnivores closely related to mink [41]. Examination of raccoon dogs and red foxes reared on the same farm in central-western Poland, revealed asymptomatic and low intensive Giardia infection in $11.1 \%$ (two out of 18) of examined raccoon dogs [42]. The parasite was not detected in any of 80 examined red foxes. As the assemblage D was confirmed in both individuals, the authors suggested (by referring to other research [43]), that it could potentially be zoonotic as another canid origin Giardia of the assemblage $\mathrm{C}$ had been isolated in humans.

Giardia spp. was also detected in $31.6 \%$ of examined wild Australian foxes [5]. PCR revealed A, D and E genotypes, but in some individuals two of them were noted at the same time (e.g. $\mathrm{A}+\mathrm{D}$, or $\mathrm{A}+\mathrm{E})$. Consequently, assemblages $\mathrm{A}, \mathrm{C}$, $\mathrm{E}$ and $\mathrm{A}+\mathrm{E}$, and the prevalence of $29.5 \%$ was confirmed in wild dogs (dingo).

Comparative studies on domestic and wild carnivorans in Romania revealed the genotype $\mathrm{D}$ as the most prevalent in dogs (76.9\%), but assemblage C and E occurred in $23.1 \%$ and $2.6 \%$ of examined individuals, respectively [44]. The only G. duodenalis cysts found in cats were assorted to genotype D. Genotype C was identified in muskrat, and genotype D in raccoon dogs and wolves. Therefore, eventual Giardia transmission from nature to the farm by guard dogs and/or cats living in surroundings should not be excluded.

Presumably, wild rodents could be involved in the transmission of giardiasis into the fur farm animals as in nature different Giardia genotypes were recently reported from these vectors in Germany.[45].

Microsporidia. Despite the ambiguous position of general systematics, these pathogens, responsible for zoonotic infection, were also detected in farm mink. Enterocytozoon bieneusi was found to be involved in diarrhoeic episodes in both animals and humans. The parasite was detected in $16.4 \%$ of blue foxes, and $4.1 \%$ of raccoon dogs in selected Chinese farms [9]. Although the authors focused mainly on the genetic identification of the isolates, and did not comment on the eventual clinical aspect (which remains to be described), they suggested that fur farm animals might serve as a reservoir of that infection for humans.

Leishmania infantum. A protozoan quite recently found to be involved in the pathogenesis of farm mink. The infection, transmitted by sand-flies, was observed in Greece and is endemic for leishmaniosis. About 2,000 adult females and 9,200 kits were reared on the farm where an outbreak of haemorrhagic pneumonia was clinically manifested in $14.9 \%$ of kits, and $38.5 \%$ of those affected died. Post-mortem examination revealed dark red consolidated lung lobes and advanced haemorrhagic/necrotic enteritis. Consequently, a picture of pyogranulomatous pneumonia was noted in HP slides of lungs. Pseudomonas aeruginosa was isolated bacteriologically in all infected animals. L. infantum DNA was detected by PCR in $21.4 \%$ of examined mink off-spring. The authors suggested L. infantum as the co-infecting pathogen, causing immuno-suppression in neonatal mink, as mink haemorrhagic pneumonia syndrome is considerably associated with decreased immunity [46].

The occurrence of $L$. infantum in nature has been reported previously in Spain (Bask Country) in several wild living fur carnivorans as: European mink, foxes, pole cats, stone martens, weasels and wild cats; but it was also noted in dogs which are considered as a reservoirs [47]. Another epidemiological survey revealed the abundance of L. infantum in wildlife of south-east Spain [48]. Using realtime PCR, researches confirmed high numbers of infections in examined animals: $45 \%$ in foxes, $30 \%$ in stone martens (Martes foina), and $20 \%$ in wild cats (Felis silvestris). Single positive individuals were also found among raccoons (Procyon lotor) and genets (Genetta genetta). Additionally, a zoonotic genotype B was detected in all examined foxes by PCR-RFLP of kinetoplast DNA. Therefore, it may be predicted that in the future (according to tendencies of climate change) the infection could be transmitted by sand-flies to northern Europe, feasibly affecting fur animals on the farm as they are permanently kept outdoors.

Despite the fact that several piroplasmid parasite species affecting the blood cells were found in wild carnivorans, including foxes, mink, etc. [49], it is very unlikely that fur animals reared in isolated farm conditions would have developed any of the piroplasmid infections, such as babesiosis, as these are transmitted by ticks.

\section{CONCLUSIONS AND RECOMMENDATIONS}

Despite the fact that fur animals are reared in suitable conditions for particular host-species, in any case of outbreak, one should focus on determining possible ways of transmission of protozoans likely to target and infect fur animals on the farm. This would make it feasible to prevent the spread within the exposed population in the future.

Farm foxes, mink, raccoon dogs, as carnivorous are fed special commercial feed based on by-products of poultry, fish, beef and pork, with some crop additives, supplements, etc. Although generally forbidden, they may illegally be given 'fresh' (not-processed) wildlife carcasses. Processed feed is calculated and prepared appropriately for particular age groups of fur animals, which is stored frozen until use, but it may also be served fresh. Thus, due to the freezing procedures, some parasites may lose their potential infectivity (e.g. T. gondii tissue cysts). Therefore, in the case of freshly prepared feed it is very important to prevent the feed from being contaminated with natural carriers of the parasitic infections, such as small rodents and other possible parasite infections carriers.

In particular, the involvement of wildlife in the epidemiological chain of toxoplasmosis as the transmission by birds reported in foxes should also be considered [26]. The disease could possibly have been introduced to farms by captive flying-foxes, as they were found to be able to develop systemic toxoplasmosis and cause respiratory distress and neurological symptoms, followed by death [50]. 
Table 1. List of protozoans involved in parasitic infection in farmed (and wild/companion) carnivorous fur animals

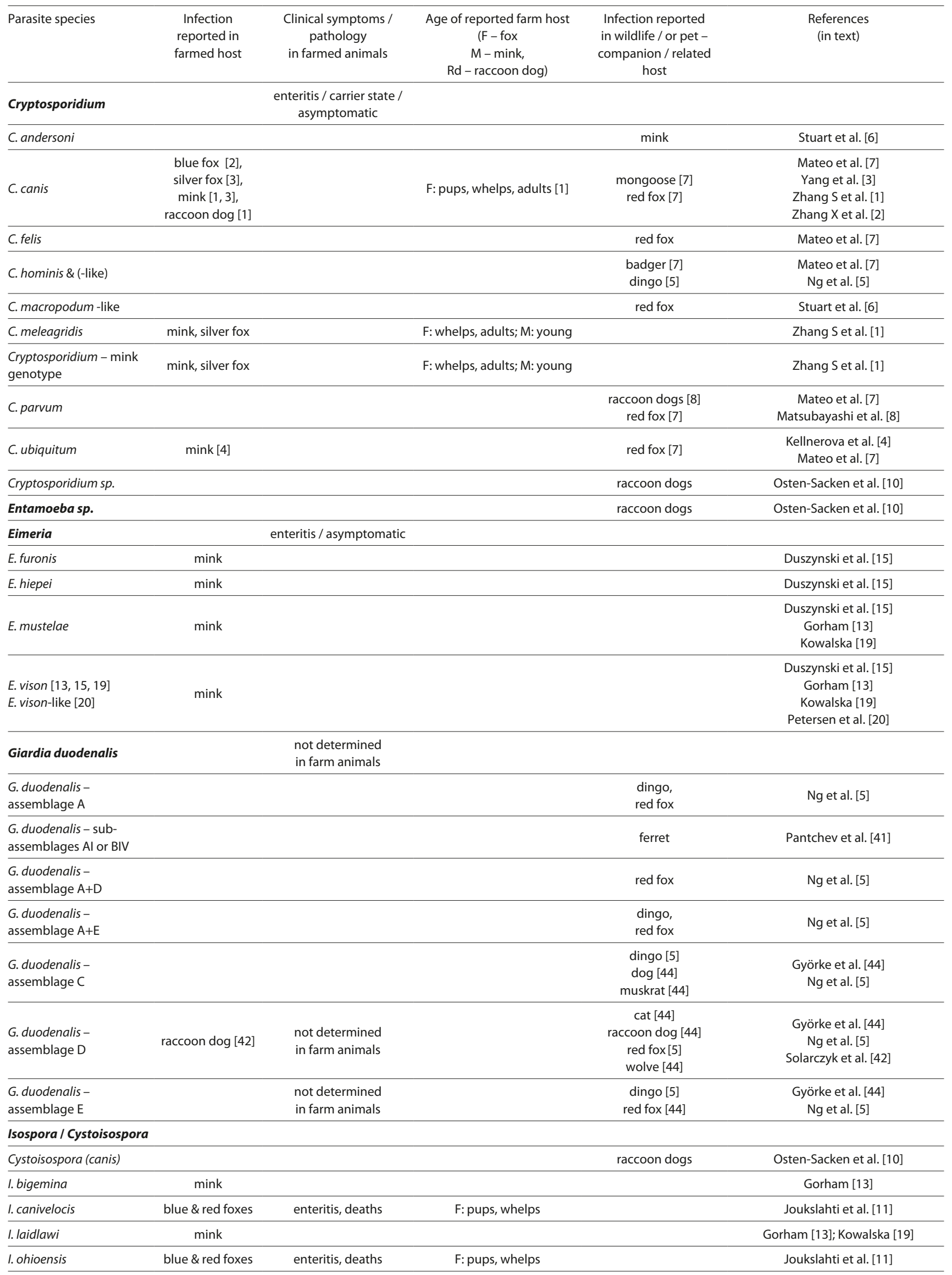




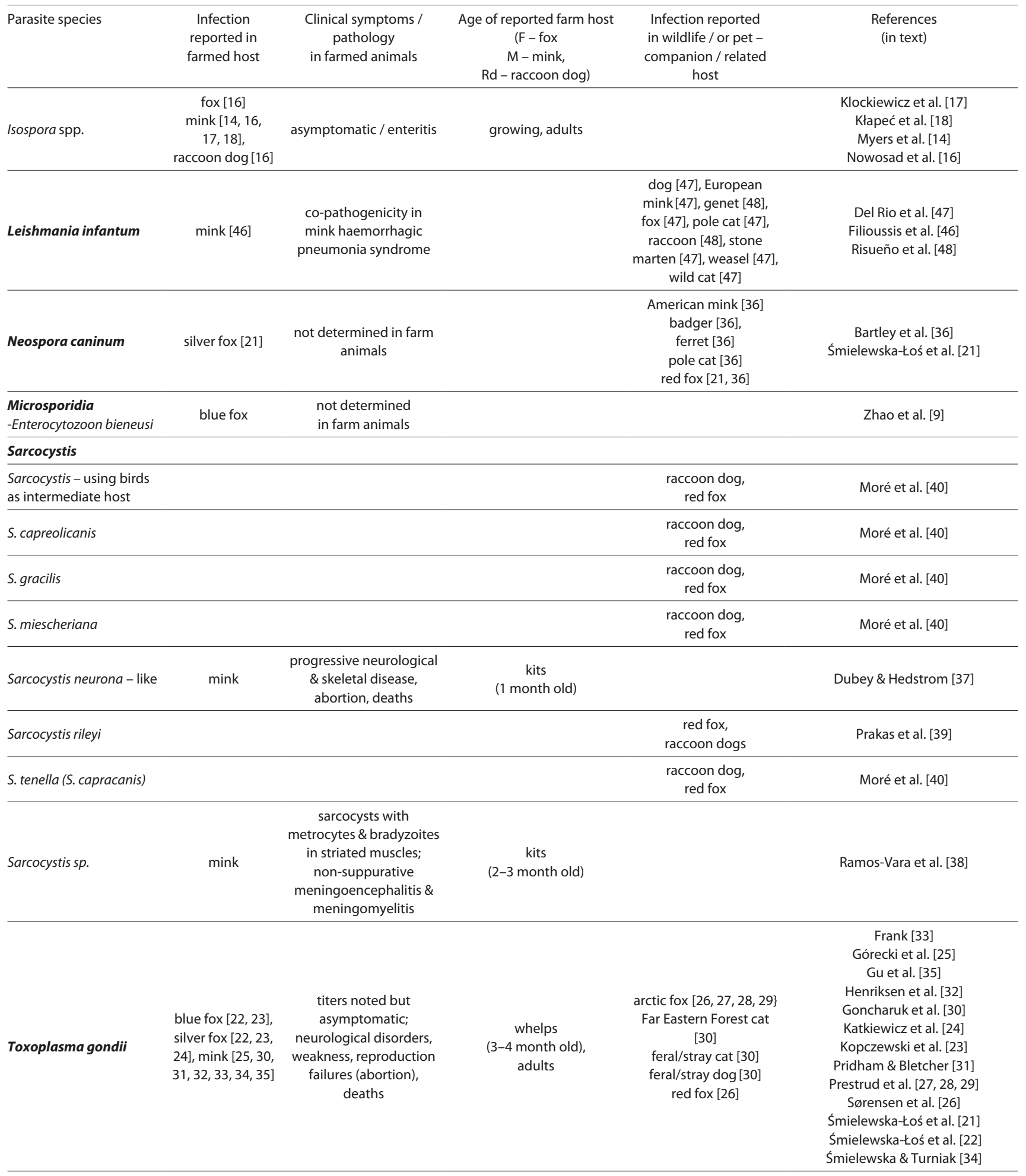

Other researchers also suggested the involvement of some bird species, such as black-headed gulls (Larus ridibundus), which were noticed feeding under silver fox facilities [11]. Consequently, it is very likely that some local bird species might transmit the coccidian oocysts from one farm into another as transport vectors. One should also consider, for example, the feasible transfer of infective oocysts, e.g. Isospora canis, by farm workers as the parasite is very common in dogs kept at home as pets.
Viewed from other perspective, it should be generally considered that human resources on the farm might be directly and/or indirectly involved in the transmission of some infections to fur farm animals. Improvements should therefore be made in differential clinical and accurate laboratory diagnostics of protozoan diseases to provide accurate health and welfare conditions in the reared animals. 


\section{REFERENCES}

1. Zhang S, Tao W, Liu C, Jiang Y, Wan Q, Li Q, et al. First report of Cryptosporidium canis in foxes (Vulpes vulpes) and raccoon dogs (Nyctereutes procyonoides) and identification of several novel subtype families for Cryptosporidium mink genotype in minks (Mustela vison) in China. Infect Genet Evol. 2016; 41: 21-25. https://doi.org/10.1016/j. meegid.2016.03.016

2. Zhang XX, Cong W, Ma JG, Lou ZL, Zheng WB, Zhao Q, et al. First report of Cryptosporidium canis in farmed Arctic foxes (Vulpes lagopus) in China. Parasit Vectors. 2016; 9: 126-129. https://doi org/10.1186/s13071-016-1396-6

3. Yang Z, Zhao W, Wang J, Ren G, Zhang W, Liu A. Molecular detection and genetic characterizations of Cryptosporidium spp. in farmed foxes, minks, and raccoon dogs in northeastern China. Parasitol Res. 2018; 117: 169-175. https://doi.org/10.1007/s00436-017-5686-5

4. Kellnerová K, Holubová N, Jandová A, Vejčík A, McEvoy J, Sak B, et al. First description of Cryptosporidium ubiquitum XIIa subtype family in farmed fur animals. Eur J Protistol. 2017; 59: 108-113. https://doi. org/10.1016/j.ejop.2017.03.007

5. Ng J, Yang R, Whiffin V, Cox P, Ryan U. Identification of zoonotic Cryptosporidium and Giardia genotypes infecting animals in Sydney's water catchments. Exp Parasitol. 2011; 128: 138-144. https://doi.org /10.1016/j.exppara.2011.02.013

6. Stuart P, Golden O, Zintl A, de Waal T, Mulcahy G, McCarthy E, et al. A coprological survey of parasites of wild carnivores in Ireland. Parasitol Res. 2013; 112: 3587-3593. https://doi.org/10.1007/s00436-013-3544-7

7. Mateo M, de Mingo MH, de Lucio A, Morales L, Balseiro A, Espí A, et al. Occurrence and molecular genotyping of Giardia duodenalis and Cryptosporidium spp. in wild mesocarnivores in Spain. Vet Parasitol. 2017; 235: 86-93. https://doi.org/10.1016/j.vetpar.2017.01.016

8. Matsubayashi M, Abe N, Takami K, Kimata I, Iseki M, Nakanishi $\mathrm{T}$, et al. First record of Cryptosporidium infection in a raccoon dog (Nyctereutes procyonides viverrinus). Vet Parasitol. 2004; 120: 171-175. https://doi.org/10.1016/j.vetpar.2004.01.007

9. Zhao W, Zhang W, Yang Z, Liu A, Zhang L, Yang F, et al. Genotyping of Enterocytozoon bieneusi in Farmed Blue Foxes (Alopex lagopus), and Raccoon dogs (Nyctereus procyonoides) in China. PLoS One 2015; 6; 10(11): e0142611.https://doi.org/10.1371/journal.pone.0142611

10. Osten-Sacken N, Słodkowicz-Kowalska A, Pacoń J, Skrzypczak Ł, Werner A. Intestinal and external parasites of raccoon dogs (Nyctereutes procyonides) in western Poland. Ann Parasitol. 2017; 63: 37-44. https:// doi.org /10.17420/ap6301.83

11. Joukslahti T, Korhonen T, Oksanen A. Coccidiosis in farmed silver foxes (Vulpes vulpes) and blue foxes (Alopex lagopus) in Finland: a case report. Acta Vet Scan. 2010; 52: S18.

12. Melhorn H (Ed.). Encyclopedic Reference of Parasitilogy. 2000, Springer-Verlag Berlin.

13. Gorham JR. Intestinal coccidiosis in mink. Fur Animal Res. 2005; 13: 94.

14. Myers GH, Foreyt WJ, Hartsough GR, Todd AC. Coccidial infections in ranch mink. J Am Vet Med Assoc. 1980; 177: 849-851.

15. Duszynski DW, Cough L, Upton SJ. Coccidia of the world. 2000, www.kstae.edu/parasitology/worldcoccidia/CARNIV2?

16. Nowosad B, Zając J, Skalska M, Kornas S. Występowanie form rozwojowych pasożytów w utylizowanych przez dżdżownice Eisenia fetida (SAV.) odchodach zwierząt futerkowych. Rocz Nauk Zoot. 2002; 29: 147-160. [in Polish]

17. Klockiewicz M, Jakubowski T, Janecka E, Długosz E. Preliminary epidemiological survey of infections by intestinal parasites in selected mink farms in Poland. Med Weter. 2013; 69: 444-447. [Summary in English]

18. Kłapeć T, Cholewa A, Kostro K, Karamon J, Zdybel J. Prevalence of intestinal parasites and Salmonella in the feces of farm-bred foxes and mink in Lublin Voivodeship as a potential risk in agricultural use. Med Weter. 2015; 71: 787-790. [Summary in English]

19. Kowalska D. Kokcydioza u norek. Zwierzęta Futerkowe. 2015; 9. [in Polish]

20. Petersen HH, Yang R, Chriél M, Hansen MS, Ryan UM. Morphological and molecular characterisation of Eimeria vison-like oocysts (Apicomplexa: Eimeriidae) in farmed mink (Neovison vison) in Denmark. Parasitol Res. 2018; 117: 2933-2939. https://doi.org/10.1007/ s00436-018-5989-1

21. Śmielewska-Łoś E, Pacoń J, Jańczak M, Płoneczka K. Prevalence of antibodies to Toxoplasma gondii and Neospora caninum in wildlife and farmed foxes (Vulpes vulpes). Electronic J Polish Agri Universit, Vet Medicine. 2003; 6(2). Wydawnictwo Uniwersytetu Przyrodniczego we Wrocławiu, ISSN 1505-0297 www.ejpau.media.pl/series/volume6/ issue 2/veterinary/art-06.html

22. Śmielewska-Łoś E, Klimentowski S, Wincewicz E, Szeleszczuk O. Toxoplasma gondii infections in farmed foxes. Med Weter 1999; 55: 527-530. [Summary in English]

23. Kopczewski A, Saba L, Nozdryn-Płotnicki Z, Sławoń J, Zoń A. Toxoplasmosis in polar foxes. Med Weter. 2001; 57: 880-882. [Summary in English]

24. Katkiewicz M, Osińska B, Jakubowski T. Toxoplasmosis in silver foxes - histopathology of septicemic disease. Życie Weter. 2012, 87: 934-936. [Summary in English]

25. Górecki MT, Galbas M, Szwed K, Przysiecki P, Dullin P, Nowicki S. Prevalence of Toxoplasma gondii Infection Diagnosed by PCR in Farmed Red Foxes, Arctic Foxes and Raccoon Dogs. Folia biologica (Kraków) 2016; 60: 61-64. https://doi.org/10.3409/fb60_1-2.61-64

26. Sørensen KK, Mørk T, Sigurdardóttir OG, Asbakk K, Akerstedt J, Bergsjø B, et al. Acute toxoplasmosis in three wild arctic foxes (Alopex lagopus) from Svalbard; one with co-infections of Salmonella enteritidis PT1 and Yersinia pseudotuberculosis serotype 2b. Res Vet Sci. 2005; 78: 161-167. https://doi.org/10.1016/j.rvsc.2004.07.010

27. Prestrud KW, Asbakk K, Fuglei E, Mørk T, Stien A, Ropstad E, et al. Serosurvey for Toxoplasma gondii in arctic foxes and possible sources of infection in the high Arctic of Svalbard. Vet Parasitol. 2007; 150: 6-12. https://doi.org/10.1016/j.vetpar.2007.09.006

28. Prestrud KW, Asbakk K, Mørk T, Fuglei E, Tryland M, Su C. Direct high-resolution genotyping of Toxoplasma gondii in arctic foxes (Vulpes lagopus) in the remote arctic Svalbard archipelago reveals widespread clonal Type II lineage. Vet Parasitol. 2008; 158: 121-128. https://doi.org/10.1016/j.vetpar.2008.08.020

29. Prestrud KW, Dubey JP, Asbakk K, Fuglei E, Su C. First isolate of Toxoplasma gondii from arctic fox (Vulpes lagopus) from Svalbard. Vet Parasitol. 2008; 151: 110-114. https://doi.org/10.1016/j.vetpar.2007.11.011

30. Goncharuk MS, Kerley LL, Naidenko SV, Rozhnov VV. Prevalence of Seropositivity to Pathogens in Small Carnivores in Adjacent Areas of Lazovsii Reserve. Biology Biulletin 2012; 39: 708-713.

31. Pridham TJ, Belcher J. Toxoplasmosis In Mink. Can J Comp Med Vet Sci. 1958; 22: 99-106.

32. Henriksen P, Dietz HH, Uttenthal A, Hansen M. Seroprevalence of Toxoplasma gondii in Danish farmed mink (Mustela vison S.). Vet Parasitol. 1994; 53: 1-5. https://doi.org/10.1016/0304-4017(94)90010-8

33. Frank RK. An outbreak of toxoplasmosis in farmed mink (Mustela vison). J Vet Diagn Invest. 2001; 13: 245-249. https://doi. org/10.1177/104063870101300310

34. Śmielewska-Łoś E, Turniak W. Toxoplasma gondii infection in Polish farmed mink. Vet Parasitol. 2004; 122: 201-206. https://doi. org/10.1016/j.vetpar.2004.02.003

35. Gu Y, Wang Z, Cai Y, Li X, Wei F, Shang L, et al. A comparative study of Toxoplasma gondii seroprevalence in mink using a modified agglutination test, a Western blot, and enzyme-linked immunosorbent assays. J Vet Diagn Invest. 2015; 27:616-620. https:// doi.org/10.1177/1040638715596033

36. Bartley PM, Wright SE, Zimmer IA, Roy S, Kitchener AC, Meredith A, et al. Detection of Neospora caninum in wild carnivores in Great Britain. Vet Parasitol. 2013; 192: 279-283. https://doi.org/10.1016/j. vetpar.2012.10.001

37. Dubey JP, Hedstrom OR. Meningoencephalitis in mink associated with a Sarcocystis neurona-like organism. J Vet Diagn Invest. 1993; 5: 467-471.

38. Ramos-Vara JA, Dubey JP, Watson GL, Winn-Elliot M, Patterson JS, Yamini B. Sarcocystosis in mink (Mustela vison). J Parasitol 1997; 83: 1198-1201.

39. Prakas P, Liaugaudaitè S, Kutkiene L, Sruoga A, Švaž S. Molecular dentification of Sarcocystis rileyi sporocysts in red foxes (Vulpes vulpes) and raccoon dogs (Nyctereutes procyonides) in Lithuania. Parasitol Res. 2015; 114: 1671-1676. https://doi.org/10.1007/s00436-015-4348-8

40. Moré G, Maksimov A, Conraths FJ, Schares G. Molecular identification of Sarcocystis spp. in foxes (Vulpes vulpes) and raccoon dogs (Nyctereutes procyonides) from Germany. Vet Parasitol. 2016; 220: 9-14. https://doi.org /10.1016/j.vetpar.2016.02.011

41. Pantchev N, Broglia A, Paoletti B, Vrhovec MG, Bertram A, Nöckler $\mathrm{K}$, et al. Occurrence and molecular typing of Giardia isolates in pet rabbits, chinchillas, guinea pigs and ferrets collected in Europe during 2006-2012. Vet Record. 2014; 175: 18. https://doi.org/10.1136/vr.102236

42. Solarczyk P, Majewska AC, Jędrzejewski S, Górecki MT, Nowicki S, Przysiecki P. First record of Giardia assemblage D infection in farmed raccoon dogs (Nyctereutes procyonides). Ann Agric Environ Med. 2016; 23: 696-698. https://doi.org/10.5604/12321966.1226869 
43. Liu H, Shen Y, Yin J, Yuan Z, Jiang Y, Xu Y, et al. Prevalence and genetic characterization of Cryptosporidium, Enterocytozoon, Giardia and Cyclospora in diarrheal outpatients in China. BMC Infect Dis. 2014; 14: 25. https://doi.org/10.1186/1471-2334-14-25

44. Györke A, Kalmár Z, Dumatriche MO, Gherman CM, Mircean V. Giardia duodenalis genotypes in domestic and wild animals from Romania identified by PCR-RLFP targeting the gdh gene. Vet Parasitol 2016; 217: 71-75. https://doi.org/10.1016/j.vetpar.2015.10.017

45. Helmy YA, Spierling NG, Schmidt S, Rosenfeld UM, Reil D, Imholt Ch et al. Occurrence and distribution of Giardia species in wild rodents in Germany. Parasit Vectors. 2018; 11: 213-226. https://doi.org/10.1186/ s13071-018-2802-Z

46. Filioussis G, Petridou E, Papadopoulos D, Karavanis E, Morgan E, Billins $\mathrm{C}$, et al. Hemorrhagic pneumonia in neonatal minks in Greece concomitant with Leishmania infantum detection. Pol J Vet Sci. 2018; 21: 405-408. https://doi.org/10.24425/122608
47. Del Rio L, Chitimia L, Cubas A, Victoriano I, De la Rua P, Gerrikagoitia $\mathrm{X}$, et al. Evidence for widespread Leishmania infantum among wild carnivores in L. infantum periendemic northern Spain. Prev Vet Med. 2014; 113: 430-435. https://doi.org/10.1016/j.vetpar.2012.10.001

48. Risueño J, Ortuño M, Pérez-Cutillas P, Goyena E, Maia E, Costes $\mathrm{C}$, Campino L, et al. Epidemiological and genetic studies suggest a common Leishmania infantum transmission cycle in wildlife, dogs and humans associated to vector abundance in Southeast Spain. Vet Parasitol. 2018; 259: 61-67. https://doi.org/10.1016/j.vetpar.2018.05.012

49. Alvorado-Rybak M, Solano-Gallego L, Millàn J. A review of piroplasmid infections in wild carnivores worldwide: importance for domestic animal health and wildlife conservation. Parasit Vectors. 2016; 9: 538-557. https://doi.org/10.1186/s13071-016-1808-7

50. Sangster CR, Gordon AN, Hayes D. Systemic toxoplasmosis in captive flying-foxes. Aust Vet J. 2012; 90: 140-142. https://doi.org/10.1111/ j.1751-0813.2011.00868.x 